\title{
Análise da Produção Escrita em Avaliação sobre Sistemas de Numeração e Código BCD
}

Maria Luisa Perdigão Diz Ramos

Edda Curi

\begin{abstract}
Resumo
Este artigo tem como objetivo classificar e analisar a produção escrita em uma questão que abrange representação numérica em diferentes sistemas de numeração e em código BCD. Essa questão faz parte de uma avaliação aplicada a 38 alunos do 1ㅇano do curso técnico de uma escola pública de Minas Gerais. A metodologia usada neste trabalho foi a análise de conteúdo da produção escrita em cada um dos quatro itens que compõem a questão. Para isso, as respostas foram classificadas como corretas, parcialmente corretas e incorretas. Com o resultado, foi possível constatar que a maioria dos alunos é capaz de representar um número em diferentes sistemas de numeração, mas comete erros ao representar esse número no código $\mathrm{BCD}$. Isso se deve ao fato de eles não compreenderem que, para representar um número em $B C D$, primeiramente, esse número precisa estar representado em decimal e, posteriormente, ser representado em $B C D$.
\end{abstract}

Palavras-chave: Avaliação da Aprendizagem, Erro, Sistemas de Numeração, Código BCD.

Abstract

Analysis on writing in Numbering Systems and BCD code evaluations

This article aims to classify and analyze written answers resulting from a question covering number representation in different number systems and BCD code. This question is part of an evaluation conducted on 38 students in their 1st year at a public technical high school of Minas Gerais. The evaluation methodology used in this study was content analysis of the written answers responding to each of the four parts that make up the question. These responses were classified as correct, partially correct, or incorrect. With the results, it was established that most students are able to represent a number in different number systems, but make mistakes representing that number in BCD code. This is due to the fact that students do not understand that in order to represent a number in BCD, first, the number needs to be represented as a decimal, and afterwards it can be represented in $\mathrm{BCD}$.

Keywords: Evaluation of Learning, Error, Number Systems, BCD code. 


\section{Introdução}

Em boa parte das escolas, a avaliação é realizada com a finalidade de se atribuir uma nota ao aprendizado do aluno. Isso normalmente ocorre uma vez ou mais durante o período letivo estabelecido pelas instituições de ensino. Ao verificar qual o valor atribuído a uma avaliação por um professor é que se percebe qual o sentido que se dá ao verbo avaliar.

Mas o que é avaliar? Qual o sentido de se avaliar? O significado de avaliar, segundo Houaiss (2001, n.p.), na acepção de verbo transitivo direto e bitransitivo é "estabelecer a valia, o valor ou o preço de"; na acepção de somente verbo transitivo direto é "ter ideia de, conjecturar sobre ou determinar a qualidade, a extensão, a intensidade etc. de". Se levarmos em consideração o primeiro significado, notamos que o sentido de avaliar está pautado na necessidade de atribuição de valores, ou seja, estabelecer notas ao aprendizado do aluno. Na segunda acepção, percebe-se que existe a necessidade de verificar a extensão ou a intensidade do aprendizado. Partindo das acepções apresentadas, descrevemos o posicionamento de Miranda e Silva (2011):

[...] o que se pratica nas escolas são avaliações que tem (sic) por finalidade auxiliar alunos e professores na tomada de consciência sobre o percurso já realizado, a distância para atingir os objetivos, os impedimentos existentes e as melhores formas de superá-los, ou são medições onde se atribui nota para atender a burocracia de classificação e sem reflexão sobre o processo. (p. 3, grifo nosso).

Ao corrigir uma avaliação, o professor não pode se deter em apenas apontar o que o aluno não aprendeu, pois, dessa forma, demonstra seu interesse de simplesmente quantificar o aprendizado do aluno, isto é, mensurar o seu conhecimento a partir dos acertos, não se preocupando, nem considerando os erros cometidos. Quando o professor usa da avaliação para dar oportunidade ao aluno de demonstrar o que sabe e o que pode fazer, ou até mesmo para analisar e identificar o que o aluno ainda não sabe fazer, ele está preocupado com o processo e não com o resultado.

Corroborando a mesma ideia, Cury e Silva (2008) afirmam que, ao avaliarmos a solução dada em um problema "não somente pelo produto final mas especialmente pelo processo de produção, podemos analisar a forma como o aluno solucionou a questão, descobrindo suas estratégias, detectando dificuldades e tecendo hipóteses sobre os erros" (p. 87).

Avaliar o aprendizado, como na maioria das vezes é feito, para se obter um resultado baseado numa forma binária, como aprovado ou reprovado, é trabalhar com avaliação do rendimento, ou seja, voltada para o resultado. Porém, se a avaliação tiver a finalidade de verificar o processo de aprendizagem do aluno, com o intuito de analisar e identificar suas dificuldades e erros e com a possibilidade de retificá-los, está se trabalhando com uma avaliação de aprendizagem. Analisando as duas situações, concordamos que,

130 DOI: Em andamento.

R. Bras. de Ensino de C\&T 
[...] a avaliação do rendimento é tomada aqui como avaliação do "produto" final, que, de certa forma, evidencia um resultado sem muita chance de ser modificado, enquanto a avaliação da aprendizagem é tomada como avaliação do e no processo, e portanto, um dos meios que subsidia a retomada da própria aprendizagem. (BURIASCO, 2002, p. 258).

A avaliação deve ser vista, tanto pelo professor quanto pelo aluno, como uma forma de contribuição ao processo de ensino-aprendizagem. Portanto, ela deve ser analisada com o intuito de ajudar o professor e o aluno a identificarem possíveis dificuldades que o último possa ter. Dessa maneira, as atividades de aprendizagem desenvolvidas em sala devem ser vistas também como atividades avaliativas, "uma vez que a avaliação é parte integrante da rotina das atividades escolares e não uma sua (sic) interrupção" (BURIASCO, 2002, p. 259).

É conveniente ressaltar que o papel da avaliação é o de investigar e não o de quantificar o conhecimento do aluno. Quando o professor usa da avaliação com aquele objetivo, ele acaba contribuindo com sua própria prática educativa, pois será capaz de dimensionar o que o aluno aprendeu e o que ele é capaz de fazer e, a partir disso, direcionar suas atividades em sala de aula. Ao perceber que aprendeu, o aluno se torna mais autônomo e confiante do seu saber. Corroborando essas ideias, Buriasco et al. (2009) afirmam que, quando a avaliação é tratada como um processo de investigação, ela

[...] deixa de ser uma prática apenas realizada sobre o estudante e passa a ser realizada também sobre e para o professor, de modo a orientar e contribuir com a aprendizagem de ambos. A avaliação ao ser impregnada da idéia de investigação deixa de ser tomada como a etapa final de um ciclo e passa a ser realizada constantemente durante todo o processo de ensino $e$ de aprendizagem. Além disso, deixa de ser vista como um elemento de ameaça e punição e passa a ser uma oportunidade de aprendizagem. (p. 78).

Ao analisar a produção escrita do aluno, o professor está em busca de algo que possa indicar as dificuldades que o aluno possui e de formas múltiplas de se resolver o que foi pedido. Assim, a análise que está sendo feita serve para identificar os erros cometidos pelo aluno, além de contribuir com a ampliação do saber do professor.

Portanto, a verificação dessa análise deve ser cuidadosa, minuciosa e atender a critérios previamente estabelecidos. Buriasco et al. (2009) descrevem alguns pontos que devem ser levados em consideração ao se realizar análises em produção escrita, tais como verificar se as dificuldades encontradas estão relacionadas à linguagem do enunciado, ao conteúdo matemático, ou a ambos; observar se todas as informações necessárias para resolução da questão estão disponíveis; certificar-se de que o enunciado está claro para o aluno e se tal enunciado serve de argumento para resolução da questão. 
Neste artigo, o objetivo é classificar e analisar a produção escrita de uma questão retirada da avaliação de Sistemas Digitais aplicada a 38 alunos do 10 ano do curso técnico de uma escola pública de Minas Gerais, que abrange representação numérica em diferentes sistemas de numeração, além da representação em código BCD (Binary-Coded-Decimal)1․ Utilizando esse tipo de análise, o professor terá a oportunidade de ajudar o aluno a adquirir o conhecimento que the falta ou ajudá-lo a descobrir os motivos que o levaram ao erro. Dessa forma, é possível melhorar a estratégia didática, fazendo as intervenções necessárias com a finalidade de retificar os erros cometidos.

\section{Algumas Considerações sobre Sistemas de Numeração e Código BCD}

Com o avanço tecnológico, hoje em dia é muito comum o uso do termo "digital". Isso se deve à intensa utilização de técnicas e circuitos digitais em computadores, nas telecomunicações, na medicina, na automação, na robótica, entre outras áreas. Devido a esse avanço, tornou-se necessária a utilização de outros sistemas de numeração, além do habitual sistema decimal.

Não é conveniente usar o sistema decimal em circuitos digitais, pois é muito complicado projetar equipamentos que operem com dez níveis diferentes de tensão, isto é, um nível de tensão para representar cada algarismo decimal. Por esse motivo, foi necessário criar um sistema numérico que pudesse ser representado com dois algarismos, pois, dessa forma, é possível trabalhar apenas com dois níveis de tensão. Devido a essa facilidade, os sistemas digitais trabalham com o sistema binário, conhecido também como sistema de base 2. Nesse sistema, os algarismos utilizados são 0 e 1 e são chamados de bits. Esse sistema tem a característica de um sistema posicional, sendo que "A principal característica dos sistemas de numeração posicionais é que o valor do dígito depende do local que ele ocupa no número." (RICO et al., 2007, p. 9, tradução nossa). O algarismo mais à direita de um número binário é chamado de LSB (Least Significant Bit) e é, portanto, o bit menos significativo, enquanto que o algarismo que fica mais à esquerda é chamado de MSB (Most Significant Bit), sendo, portanto, o bit mais significativo. Sendo o sistema binário um sistema posicional, logo cada bit possui certo peso, de acordo com a posição relativa ao LSB (TOCCl et al., 2011).

Às vezes, a representação binária de um número é muito extensa. Dessa forma, torna-se necessária a utilização de outros sistemas numéricos chamados de octal e hexadecimal. Então, quando a representação de um número na base 2 for muito extensa, pode-se optar por representá-lo na base 8 (sistema octal) ou na base 16 (sistema hexadecimal). O sistema octal

\footnotetext{
${ }^{1} \mathrm{~A}$ tradução encontrada nos livros didáticos de Sistemas Digitais para o código BCD é "Decimal Codificado em Binário".

132 DOI: Em andamento.

R. Bras. de Ensino de C\&T
} 
possui 8 algarismos que vão de 0 até 7 , enquanto que o sistema hexadecimal possui 16 símbolos possíveis para os dígitos que vão de 0 até $\mathrm{F}$. Os 10 primeiros símbolos são representados pelos dígitos de 0 até 9 , seguidos pelas letras A, B, C, D, E e F (TAUB, 1984).

Os sistemas octal e hexadecimal possuem uma relação particular com o sistema binário. Cada algarismo no sistema octal pode ser representado por três algarismos binários $\left(2^{3}=8\right)$ e cada algarismo no sistema hexadecimal pode ser representado por quatro algarismos binários $\left(2^{4}\right.$ = 16). Isso facilita muito a conversão numérica entre os sistemas binário-octal, bináriohexadecimal e vice-versa.

A conversão numérica do sistema binário para o sistema octal é feita com agrupamentos de três em três bits da direita para esquerda e substituindo cada grupo pelo algarismo octal correspondente. No caso da conversão de binário para hexadecimal, o agrupamento é feito de quatro em quatro bits e substituindo cada grupo pelo hexadecimal correspondente. A conversão numérica em sentido contrário, isto é, octal-binário é feita substituindo cada algarismo octal pelo binário equivalente de três bits e, no caso de hexadecimal-binário, cada algarismo hexadecimal pelo binário equivalente a quatro bits. Caso seja necessário passar de octal para hexadecimal ou vice-versa, normalmente se faz a conversão intermediária por meio do sistema binário (IDOETA E CAPUANO, 1984).

Existem situações em que são necessárias conversões de um número decimal (representação utilizada no mundo real) em um número binário. Exemplificando, quando se digita um número no computador, "o circuito interno dessas máquinas converte o número decimal em um valor binário" (TOCCl et al., 2011, p. 23). Da mesma forma, existem situações de conversão de um número binário em decimal, especialmente, quando tem que ser apresentado ao mundo real. Assim, é necessária a conversão entre as bases.

Além do sistema binário, os sistemas octal e hexadecimal também são considerados sistemas posicionais. Então, a conversão de um número de alguma dessas bases para a base decimal "será à soma de cada dígito multiplicado pela potência da base correspondente à posição em que ocupa no número" (RICO et al., 2007, p. 9, tradução nossa).

Para a conversão do sistema numérico decimal em binário, basta realizar divisões sucessivas pelo número decimal 2 , até que o último quociente seja 0 . A resposta é obtida de modo inverso, isto é, o último resto é o algarismo MSB na representação binária e o primeiro resto é o algarismo LSB (TAUB, 1984). Quando um número decimal é representado por seu número binário equivalente, se diz que é uma codificação em binário puro. Da mesma forma, para se converter decimal em octal, basta realizar divisões sucessivas por 8 e, para hexadecimal, divisões sucessivas por 16 .

Essas conversões decimal-binário e binário-decimal são demoradas e complicadas de serem realizadas, principalmente para números muito grandes. Logo, é muito importante o uso de um 
método de conversão mais rápido. Um método muito utilizado é o denominado código $B C D$ (Decimal Codificado em Binário, na tradução). Segundo Tocci et al. (2011), a representação de cada dígito de um número decimal por seu equivalente em binário, o resultado será o código $B C D$. Nesse código, cada algarismo decimal é representado por quatro algarismos binários, pois o maior algarismo decimal, que é o algarismo 9, precisa de quatro algarismos binários para representá-lo (1001).

Das 16 possíveis representações com 4 bits, são utilizadas nesse código apenas as 10 primeiras, ou seja de 0000 até 1001. Assim, o código BCD não utiliza os números binários 1010, $1011,1100,1101,1110$ e 1111, pois não se trata de representações de algarismos decimais portanto, essas representações são chamadas de combinações proibidas em BCD. Se alguma dessas combinações proibidas aparecerem em uma máquina que utiliza $B C D$, é indicado um sinal de erro.

\section{Metodologia da pesquisa}

A questão aqui analisada faz parte de uma avaliação da disciplina de Sistemas Digitais que foi aplicada pela primeira autora deste artigo, professora da turma. Essa disciplina está presente na grade curricular do 1 o ano do curso técnico de nível médio modalidade integrada de uma escola pública de Minas Gerais, fazendo também parte de diversas outras grades curriculares em diferentes modalidades, em diferentes níveis de ensino e em diversos cursos em várias escolas.

No início da análise, foi verificado se todos os alunos responderam aos quatro itens da questão. Esses itens serão denominados aqui por: item $1 \mathrm{~A}$, item $1 \mathrm{~B}$, item $1 \mathrm{C}$ e item $1 \mathrm{D}$. Antes de devolver as avaliações aos alunos, a questão analisada foi fotocopiada e organizada de tal maneira a formar o corpus do qual será apresentada a análise (CURY, 2008).

A metodologia de pesquisa utilizada foi a análise de conteúdo da produção escrita dessa questão, além da categorização. Inicialmente, foi realizada uma "leitura flutuante" sobre as respostas apresentadas por cada aluno, que, segundo Bardin (1977), constitui o primeiro contato com os documentos a serem analisados; esse movimento teve como finalidade uma análise inicial das respostas corretas, parcialmente corretas e incorretas apresentadas em cada item da questão.

Buriasco et al.(2003), além de Leivas e Cury (2010), apresentam uma forma de avaliar a produção escrita dos alunos. Para realização desse tipo de análise, os autores empregam os códigos utilizados na correção das provas do Programa Internacional sobre Avaliação de Estudantes (PISA).

No Manual para Correção das Provas com Questões Abertas de Matemática, Buriasco et al. (2003) utilizam-se de codificação para pontuar as questões respondidas pelos alunos, sendo essa 
codificação composta de indicação de créditos e de uso de código numérico de dois ou três dígitos.

$\mathrm{Na}$ indicação de créditos, são utilizados os seguintes códigos: "crédito completo" (código 2) - indica a resolução do professor e resoluções alternativas à do professor apresentadas de forma correta pelos alunos; "crédito parcial" (código 1) - indica resoluções parcialmente corretas; e "nenhum crédito" (código 0 e 9) - indica resoluções incorretas e omissões, respectivamente.

O uso de código numérico de dois ou três dígitos tem a finalidade de apontar as várias maneiras de resolução apresentadas pelos alunos. Por exemplo, uma resposta apresentada de forma correta pode receber o código 2.1, 2.2 ou 2.10 etc., em que o primeiro algarismo indica que os alunos receberam "crédito completo" e o(s) segundo/terceiro algarismo(s) indica(m) a variedade de respostas apresentadas.

Leivas e Cury (2010) utilizam da indicação de crédito em seu trabalho para analisar a produção escrita da seguinte maneira: código 2 - solução correta; código 1 - solução parcialmente correta; código 0 - solução incorreta; e código 9 - ausência de solução. Para as questões parcialmente corretas e as incorretas, os autores fizeram a análise quanto aos erros cometidos.

Para este artigo, a partir da leitura realizada e usando critérios similares aos trabalhos de Buriasco et al. (2003) e Leivas e Cury (2010), foram estabelecidos quatro códigos para análise de conteúdo da produção escrita dos alunos, conforme definido a seguir:

$>$ Código 2: solução correta.

$>$ Código 1: solução parcialmente correta.

$>$ Código 0: solução incorreta.

> Código 9: ausência de solução.

As diferentes soluções apresentadas dentro de cada código receberão um dígito a mais para diferenciar uma das outras. A solução correta apresentada pelo código 2 será a indicada pela professora e considerada como padrão (BURIASCO et al., 2003).

\section{Apresentação e análise dos dados}

$O$ aluno será referenciado neste trabalho apenas pela letra $A$, seguida de um número, com o intuito de preservar a identidade dele. A partir da categorização realizada, apresentamos no Gráfico 1 a distribuição das respostas dadas por itens da questão, segundo os códigos apresentados na metodologia de pesquisa. 


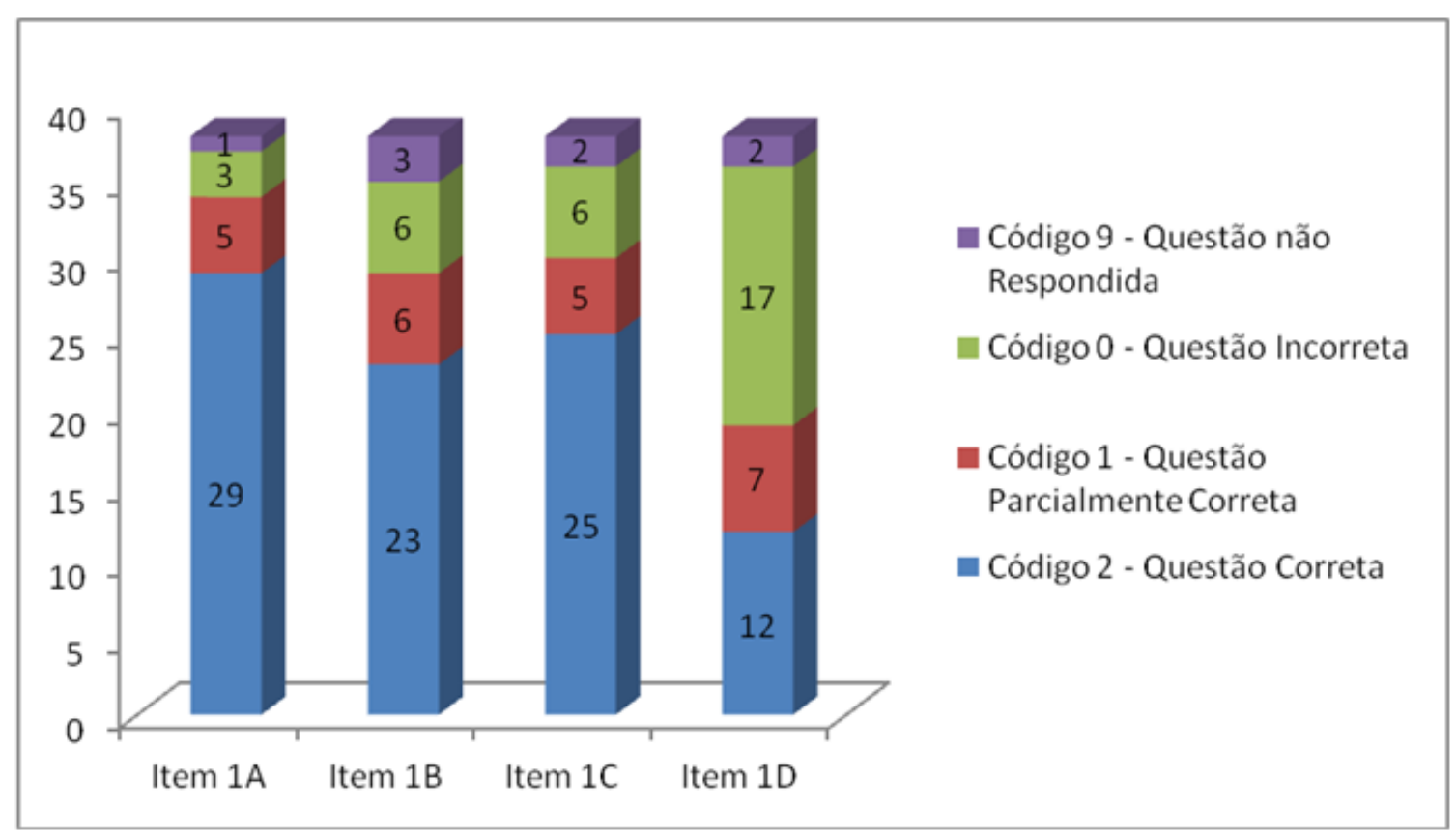

Gráfico 1 - Quantidade de respostas apresentadas em cada item da questão, identificadas pelos códigos

A apresentação e a análise de cada item da questão serão expostas na seguinte ordem: enunciado do item; apresentação da resolução adotada como padrão - Código 2 (para exibição dessas resoluções foram utilizadas respostas dadas pelos alunos); descrição das respostas corretas - Código 2.X; descrição das respostas parcialmente corretas - Código 1.X; finalizando, descrição das respostas incorretas - Código 0.X. Usaremos o código 0.5 para indicar as soluções incorretas e que não foi possível identificar a solução dada pelo aluno. Será citada a quantidade de respostas identificadas por códigos. Priorizaremos a ilustração das respostas incorretas apresentadas no código $0 . X$ do item 1D, por ter sido este o que apresentou o maior percentual de erros.

Item $1 A-$ Representar o número hexadecimal $5 E_{16}$ em binário puro

Código 2: Conversão de cada algarismo hexadecimal em grupos de 4 algarismos binários (FIGURA 1).

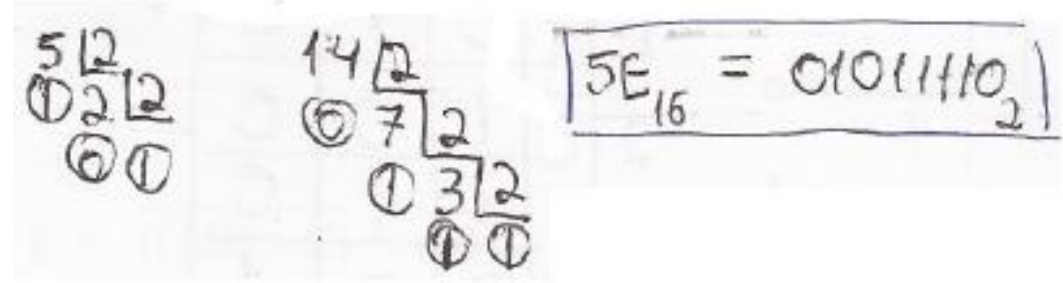

Figura 1 - Resolução correta apresentada por A15 e adotada como padrão 
Quadro 1 - Soluções apresentadas no item 1A da questão

\begin{tabular}{|l|l|}
\hline Código & Descrição da solução \\
\hline 2.1 & Conversão de hexadecimal para decimal seguida de decimal para binário. \\
\hline 1.1 & $\begin{array}{l}\text { Conversão de cada algarismo hexadecimal em binário, errando na conversão de } \\
\text { um dos algarismos hexadecimal em binário. }\end{array}$ \\
\hline 1.2 & $\begin{array}{l}\text { Conversão de hexadecimal para decimal seguida de decimal para binário, errando } \\
\text { na divisão do decimal para binário. }\end{array}$ \\
\hline 0.1 & $\begin{array}{l}\text { Desmembramento do algarismo } \mathrm{E}_{16} \text { em dois algarismos decimais, seguida da } \\
\text { representação desse número em binário. }\end{array}$ \\
\hline 0.2 & $\begin{array}{l}\text { Desmembramento do algarismo } \mathrm{E}_{16} \text { em dois algarismos decimais, seguida de } \\
\text { divisões sucessivas por } 2 \text { para encontrar o binário. }\end{array}$ \\
\hline
\end{tabular}

A seguir, será apresentada uma análise a partir da resolução padrão descrita no código 2 (Item $1 \mathrm{~A}$ ) e as resoluções descritas no Quadro 1. A resolução padrão que é a maneira mais direta e rápida de conversão de um número hexadecimal para binário foi apresentada por vinte alunos, enquanto que a segunda alternativa, indicada pelo código 2.1, foi realizada por nove alunos. Essa conversão descrita no código 2 é a alternativa mais indicada para se transformar um número hexadecimal em binário, pois basta consultar uma tabela que possua a representação binária dos algarismos hexadecimal ou converter cada algarismo hexadecimal em binário, obtendo-se assim, mais rapidamente, a resposta final. A segunda maneira é mais lenta, pois envolve diversos tipos de operações.

A solução parcialmente correta representada pelo código 1.1 foi dada por quatro alunos, sendo que três converteram o algarismo $\mathrm{E}_{16}$ para $1111_{2}$ e um para $1100_{2}$, além de um deles ter convertido o algarismo $5_{16}$ para $0100_{2}$. Esses alunos demonstraram desconhecer que os 16 símbolos do sistema de numeração hexadecimal são representados pelos dígitos de 0 a 9 mais as letras $A, B, C, D, E$ e $F$, sendo $A=10=1010_{2}, B=11=1011_{2}, C=12=1100_{2}, D=13=1101_{2}, E=14$ $=1110_{2}$ e $F=15=1111_{2}$ (TAUB, 1984). $O$ único aluno que apresentou a solução parcialmente correta descrita no código 1.2 errou na divisão sucessiva do número 94 por 2 encontrando como resultado $111110_{2}$.

Um aluno apresentou a solução incorreta descrita no código 0.1 , pois desmembrou o algarismo $E_{16}$ em 1 e 5 apresentando a resposta para o número $515_{16}=010111110101_{2}$, além de cometer outro erro ao representar o binário correspondente ao algarismo 1. Ao desmembrar o algarismo $E_{16}$, os alunos demonstram que não compreendem que $E_{16}$ é somente um dígito hexadecimal, pois "Cada dígito hexa é convertido no equivalente binário de 4 bits" (TOCCl et al., 2011 , p. 29, grifo no original); nesse caso, o equivalente seria 1110. A solução incorreta - código

R. B. E. C. T., vol 8, núm. 4, set-dez.2015 ISSN - 1982-873X

DOI: Em andamento. 
0.2 - foi dada por dois alunos, sendo que um desmembrou o algarismo $E_{16}$ em 1 e 4, dividiu o número encontrado 514 sucessivamente por 2, apresentando o resultado incorreto igual a $0100000001_{2}$, pois ordenou os algarismos depois da divisão na ordem inversa. O outro desmembrou o algarismo $\mathrm{E}_{16}$ em 1 e 2 e dividiu o número encontrado 512 por 2, sucessivamente, apresentando o resultado $100000000_{2}$. Para esses alunos, a conversão de hexadecimal para decimal é simplesmente o desmembramento do algarismo $E_{16}$ pelo seu valor correspondente. Somente um dos 38 alunos deixou a resposta desse item em branco.

Item $1 B$ - Representar o número hexadecimal $5 E_{16}$ em octal

Código 2: Conversão do hexadecimal em binário puro, depois para cada grupo de três bits substituir pelo octal correspondente (FIGURA 2).

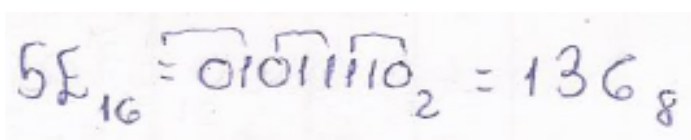

Figura 2 - Resolução correta apresentada por A4 e adotada como padrão

Quadro 2 - Soluções apresentadas no item 1B da questão

\begin{tabular}{|c|c|}
\hline Código & Descrição da solução \\
\hline 2.1 & Conversão do hexadecimal para decimal e depois para octal. \\
\hline 1.1 & $\begin{array}{l}\text { Conversão do hexadecimal em binário puro, depois para cada grupo de três bits } \\
\text { substituir pelo octal correspondente, errando na conversão do binário. }\end{array}$ \\
\hline 1.2 & $\begin{array}{l}\text { Conversão do hexadecimal em binário puro, depois para cada grupo de três bits } \\
\text { substituir pelo octal correspondente, errando ao substituir um dos grupos binários } \\
\text { pelo octal correspondente. }\end{array}$ \\
\hline 1.3 & Conversão do hexadecimal para decimal e depois para octal, errando na divisão. \\
\hline 0.1 & Conversão do hexadecimal em binário e não em octal. \\
\hline 0.2 & $\begin{array}{l}\text { Desmembrou o algarismo } \mathrm{E}_{16} \text { em dois algarismos decimais e depois representou } \\
\text { cada algarismo decimal em três algarismos binários. }\end{array}$ \\
\hline 0.3 & $\begin{array}{l}\text { Desmembrou o algarismo } \mathrm{E}_{16} \mathrm{em} \text { dois algarismos decimais e depois representou } \\
\text { em octal. }\end{array}$ \\
\hline 0.4 & $\begin{array}{l}\text { Conversão do hexadecimal para decimal de forma errada e seguida de conversão } \\
\text { incorreta para octal. }\end{array}$ \\
\hline 0.5 & Não foi possível identificar a resolução dada pelo aluno. \\
\hline
\end{tabular}

138 DOI: Em andamento.

R. Bras. de Ensino de C\&T 
A partir do binário apresentado no item $1 \mathrm{~A}$, é possível encontrar o octal correspondente consultando uma tabela que contenha os algarismos octais e seus binários correspondentes. Essa é, portanto, a solução mais rápida (Código 2 - Item 1B) e foi apresentada por treze alunos. A seguir, serão analisadas as resoluções descritas no Quadro 2 referentes ao Item 1B da questão. A resolução representada pelo código 2.1 foi realizada por dez alunos, sendo essa forma de conversão a mais demorada, pois envolve diversos tipos de operações. As soluções parcialmente corretas representadas pelo código 1.1 foram dadas por quatro alunos, e o erro cometido foi consequência de outro: representação binária incorreta no item $1 \mathrm{~A}$. Dois apresentaram a resposta $137_{8}$ e os outros $164_{8}$ e $76_{8}$. O erro cometido pelo aluno cuja resposta está codificada em 1.2, foi que ele substituiu 001 por 2 , apresentando como resposta $236_{8}$. A resposta codificada em 1.3 foi apresentada por um aluno ao errar na divisão de decimal para octal, chegando à resposta $836_{8}$.

Um aluno apresentou a solução incorreta correspondente ao código 0.1, cujo resultado foi $5 \mathrm{E}_{16}=001011110_{8}$. Para chegar a essa solução, ele usou a resposta do item $1 \mathrm{~A}$, separou em grupos de três bits e os reescreveu sem nenhuma alteração indicando a base 8 . Isso demonstra que ele desconhece que cada grupo de três bits corresponde a um único dígito octal (TAUB, 1984)

A solução incorreta descrita no código 0.2 foi realizada por um aluno. 0 erro cometido foi o desmembramento do algarismo $\mathrm{E}_{16}$ em dois algarismos - 1 e 5 -, apresentando como resposta $5 \mathrm{E}_{16}=515=1010010101$, errando também ao representar o algarismo 5 (menos significativo) com 4 algarismos binários. A solução, além de incorreta, também não foi concluída, pois, após converter o número para binário, o aluno deveria passá-lo para octal.

Na solução incorreta - código 0.3 -, o único aluno desmembrou o algarismo $\mathrm{E}_{16}$ em dois algarismos - 1 e 4, resultando no número 514, o qual foi dividido sucessivamente por 8 encontrando o resultado $2001_{8}$, errando também ao apresentar o resultado de forma inversa. A única solução incorreta representada pelo código 0.4, além do aluno errar na representação decimal do número $5 \mathrm{E}_{16}=65$, ao convertê-lo de decimal para octal, usou o método de conversão de octal para decimal e apresentou como resultado $53_{8}$. Não foi possível identificar as soluções incorretas - código 0.5 - apresentadas por dois alunos. Três dos 38 alunos não responderam esse item da questão.

Item $1 C-$ Representar o número hexadecimal $5 E_{16}$ em decimal

Código 2: Conversão usando a potência da base 16 para cada algarismo hexadecimal (FIGURA 3). 


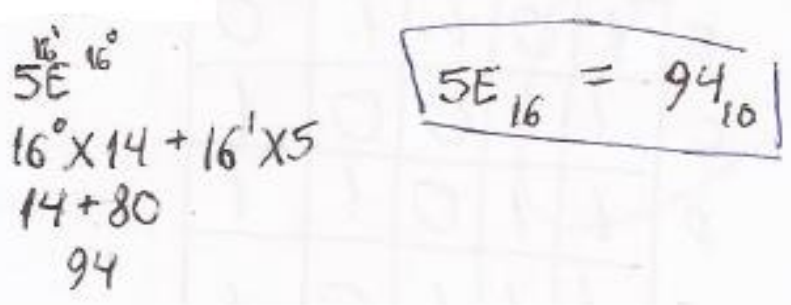

Figura 3 - Resolução correta apresentada por A15 e adotada como padrão

Quadro 3-Soluções apresentadas no item 1C da questão

\begin{tabular}{|c|c|}
\hline Código & Descrição da solução \\
\hline 2.1 & $\begin{array}{l}\text { Conversão do octal encontrado no item 1B para decimal usando a potência da } \\
\text { base } 8 .\end{array}$ \\
\hline 2.2 & $\begin{array}{l}\text { Conversão do binário encontrado no item } 1 \mathrm{~A} \text { para decimal usando a potência da } \\
\text { base } 2 .\end{array}$ \\
\hline 1.1 & $\begin{array}{l}\text { Conversão do octal encontrado no item 1B para decimal usando a potência da } \\
\text { base } 8 \text {, errando na operação realizada. }\end{array}$ \\
\hline 1.2 & $\begin{array}{l}\text { Conversão usando a potência da base } 16 \text { para cada algarismo hexadecimal, } \\
\text { errando ao escrever o valor de } E_{16} \text { na expressão. }\end{array}$ \\
\hline 1.3 & $\begin{array}{l}\text { Conversão do hexadecimal para decimal, errando ao montar a expressão } \\
\text { correspondente à decomposição do número. }\end{array}$ \\
\hline 0.1 & Desmembrou o algarismo $\mathrm{E}_{16}$ em dois algarismos decimais. \\
\hline 0.2 & $\begin{array}{l}\text { Conversão do hexadecimal para decimal, usando a base decimal em vez da base } \\
\text { hexadecimal, e representou o } E_{16} \text { incorretamente. }\end{array}$ \\
\hline 0.3 & Conversão do hexadecimal para binário e representou o $\mathrm{E}_{16}$ incorretamente. \\
\hline 0.5 & Não foi possível identificar a resolução dada pelo aluno. \\
\hline
\end{tabular}

Prosseguiremos com uma análise a partir da resolução padrão descrita no código 2 (Item 1C) e as resoluções descritas no Quadro 3. Tanto a resolução padrão quanto as resoluções representadas pelos códigos 2.1 e 2.2 possuem o mesmo grau de complexidade para conversão, pois em todas elas o processo a ser seguido é a potenciação da base em que se encontra o número, logo, as operações a serem realizadas são as mesmas. No código 2, foram computadas 22 respostas; no 2.1 , duas respostas; e no 2.2 , uma resposta.

Um aluno apresentou solução parcialmente correta, conforme código 1.1, errando ao somar $64+24+6=104$. Três apresentaram soluções parcialmente corretas, conforme código 1.2, 140 DOI: Em andamento. R. Bras. de Ensino de C\&T 
sendo que um fez a conversão considerando o algarismo $\mathrm{E}_{16}$ como 15 , chegando ao resultado 95; o outro como 12, apresentando o resultado 92; e o último como 5, apresentando o resultado 85.

O aluno que apresentou a solução parcialmente correta representada pelo código 1.3, errou ao escrever a expressão referente à conversão do número, conforme Figura 4, demonstrando ter dificuldades em trabalhar com potência, além de ter atribuído valor incorreto ao algarismo $\mathrm{E}_{16}$.

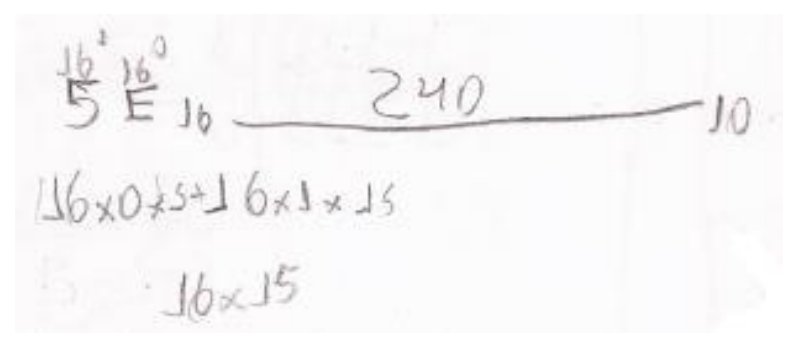

Figura 4-Resolução apresentada por A21

Dois alunos apresentaram soluções incorretas indicadas pelo código 0.1 , sendo suas respostas, 515 e 514. Para esses alunos, a conversão de hexadecimal para decimal seria simplesmente substituir o algarismo $\mathrm{E}_{16}$ pelos valores correspondentes: 15 e 14 .

Duas soluções incorretas são do tipo código 0.2 e apresentaram as respostas 62 e 65 . Nesse tipo de solução, os alunos demonstraram saber que o sistema hexadecimal é um sistema posicional, mas não levaram em consideração a base 16 em que o número estava representado, demonstrando desconhecer que "Um número hexa pode ser convertido em seu equivalente decimal pelo fato de a posição de cada dígito hexa ter um peso que é uma potência de 16" (TOCCI et al., 2011, p. 28).

Um aluno apresentou solução incorreta do tipo código 0.3 , tendo encontrado a resposta 01011111, demonstrando que não se preocupou com o enunciado, pois representou cada algarismo hexa em binário, além de errar o valor do algarismo $\mathrm{E}_{16}$.

Não foi possível identificar a solução incorreta apresentada por um aluno (código 0.5). Somente dois dos 38 alunos não responderam esse item da questão.

Item $1 D$ - Representar o número hexadecimal $5 E_{16}$ em $B C D$

Código 2: Conversão para decimal, seguida pela substituição de cada algarismo decimal pelo binário correspondente (FIGURA 5). 

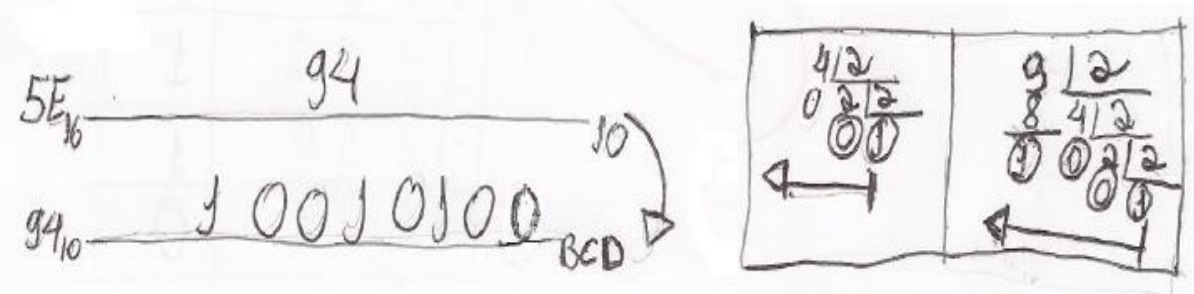

Figura 5 - Resolução correta apresentada por A5 e adotada como padrão

Quadro 4 - Soluções apresentadas no item 1D da questão

\begin{tabular}{|l|l|}
\hline Código & Descrição da solução \\
\hline 1.1 & Conversão para o decimal, errando ao representar um dos algarismos em binário. \\
\hline 1.2 & Conversão errada para decimal, errando na resposta final. \\
\hline 1.3 & $\begin{array}{l}\text { Conversão para decimal, seguida pela substituição de cada algarismo decimal pelo } \\
\text { binário correspondente, errando ao inverter as ordens dos algarismos decimais. }\end{array}$ \\
\hline 0.1 & $\begin{array}{l}\text { Conversão de hexadecimal para binário. } \\
\text { pesmembrou o algarismo E E } 16 \text { em dois algarismos decimais em seguida converteu }\end{array}$ \\
\hline 0.3 & $\begin{array}{l}\text { Conversão do hexadecimal direto para binário puro e não para BCD. Alegou que a } \\
\text { conversão não é possível. }\end{array}$ \\
\hline 0.5 & Não foi possível identificar a resolução dada pelo aluno. \\
\hline
\end{tabular}

Pelo fato de o BCD ser um código que representa cada dígito de um número decimal por seu equivalente em binário, só existe uma única forma de conversão a ser seguida. O primeiro passo é converter o número hexadecimal para decimal e, em seguida, representar cada algarismo decimal pelo binário correspondente, utilizando 4 bits para cada dígito. Logo, a solução padrão (Código 2 - Item 1D) é a única forma de resolução correta e foi apresentada por doze alunos.

A seguir, iremos analisar as resoluções descritas no Quadro 4 referentes ao Item 1D da questão. As soluções parcialmente corretas apresentadas por três alunos e representadas pelo código 1.1 foram as codificações do algarismo 9 em BCD, sendo incorretamente representado por 1010 e 1101 . As respostas identificadas pelo código 1.2 foram dadas por três alunos, que erraram na conversão de hexadecimal para decimal, gerando, então, a representação incorreta em BCD. As respostas apresentadas foram: $5 \mathrm{E}_{16}=95=10010101_{(\mathrm{BCD})}, 5 \mathrm{E}_{16}=92=10010010_{(\mathrm{BCD})}$ e $5 \mathrm{E}_{16}=85=$ $10000101_{(B C D)}$.

A solução parcialmente correta dada por um aluno, referente ao código 1.3, deveu-se à inversão da representação dos algarismos decimais em binário; logo, a resposta dada no item da 
questão foi $5 \mathrm{E}_{16}=94=001001001$, além disso, o aluno representou o algarismo 4 com 5 bits ao invés de 4 bits.

Três alunos apresentaram soluções incorretas, conforme código 0.1 , sendo as respostas $01011110_{B C D}, 01011101$ e $1011112_{2}$. Conforme Tocci et al. (2011), "Se cada dígito de um número decimal for representado por seu equivalente em binário, o resultado será um código denominado decimal codificado em binário" (p. 31, grifo no original). Então, esses alunos erraram por desconhecerem que não se pode converter um número hexadecimal direto em BCD. Além disso, um deles apresentou a resposta como se fosse base 2 , demonstrando não ter compreendido o enunciado do item.

Os três alunos que responderam incorretamente, conforme código 0.2 , desmembraram o algarismo $E_{16}$ nos algarismos 1 e 4 e converteram cada um dos algarismos em binário. Para esses alunos, a conversão hexadecimal para decimal é realizada com o desmembramento do algarismo $E_{16}$. A solução dada por um deles está representada na Figura 6 .

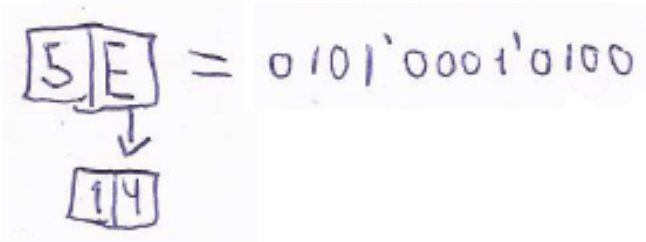

Figura 6-Resolução apresentada por A32

O maior número de soluções incorretas foi apresentado por dez alunos e estão descritas no código 0.3. Esses alunos não compreendem a diferença existente entre um número codificado em binário puro e a representação de um número decimal em código BCD (Decimal Codificado em Binário), por isso substituiram diretamente cada algarismo hexadecimal pelo binário correspondente $-5 \mathrm{E}_{16}=01011110_{2}-$, encontrado, assim, o binário puro do número $5 \mathrm{E}_{16}$ e não o código BCD solicitado. O mesmo erro já havia sido cometido pelos alunos que apresentaram as soluções descritas nos códigos 0.1 e 0.2. No entanto, a solução apresentada pelos alunos, com resposta representada pelo código 0.3 , ao descreverem que $5 \mathrm{E}_{16}=01011110_{2}$, se depararam com os grupos 0101 e 1110, e citaram que o grupo 1110 pertence ao grupo de combinações proibidas em BCD. Dessa forma, chegaram à conclusão errônea de que não é possível representar o número $5 \mathrm{E}_{16}$ em $\mathrm{BCD}$. A Figura 7 representa a solução dada por um dos alunos. 


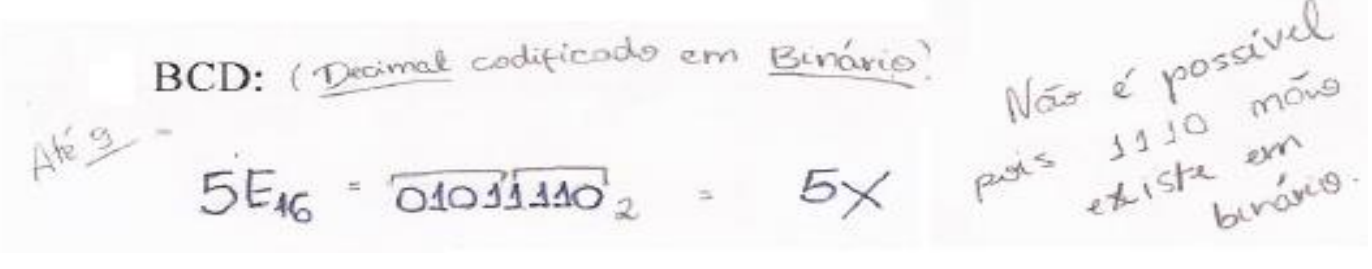

Figura 7-Resolução apresentada por A17

Mesmo escrevendo o significado da sigla BCD no item da questão, o aluno codificou cada algarismo hexadecimal em binário, desconsiderando sua própria anotação. Se o número hexadecimal tivesse sido convertido antes para decimal $5 \mathrm{E}_{16}=94=10010100_{(\mathrm{BCD})}$, ele teria percebido que não existe nenhum grupo de 4 bits pertencente ao grupo de combinações proibidas.

Não foi possível identificar a solução incorreta dada por um único aluno representada pelo código 0.5. Somente dois dos 38 alunos não responderam ao item da questão.

\section{Considerações finais}

Ao analisar uma avaliação realizada pelo aluno, podemos identificar diferentes formas de resolução de uma questão, além de detectar e identificar o erro, em vez de evitá-lo. Os erros podem ser ocasionados por vários motivos, que podem ser identificados quando o professor analisa o processo e não só o resultado. Ramos e Curi (2013) citam que "a partir dos erros cometidos pelo aluno ou de um questionamento a respeito do conteúdo ensinado, o professor pode perceber que o entendimento sobre o assunto abordado não ficou claro." (p. 233). Assim, "cabe ao professor investigar, questionar e procurar entender o que levou o aluno a cometer 0 erro e então interferir em sua prática pedagógica." (p. 233).

Considerando a análise dos dados aqui realizada, as soluções dos itens $1 \mathrm{~A}$ e $1 \mathrm{C}$, similares à solução padrão descrita pelo código 2 , foram apresentadas por mais da metade dos alunos. As soluções definidas como padrão e apresentadas nas questões $1 \mathrm{~A}$ e $1 \mathrm{~B}$ são as de mais fácil conversão, portanto, são as mais utilizadas em sistemas digitais, pois as máquinas que processam conversão dessa forma apresentam respostas mais rápidas. Foi possível perceber que a maioria dos alunos que utilizou a conversão mais rápida de hexadecimal para binário no item $1 \mathrm{~A}$ resolveu também o item 1B pelo método mais rápido, isto é, converteu o hexadecimal para binário para depois converter em octal.

Podemos notar que o aluno não se preocupou em verificar se o resultado encontrado era compatível com o sistema numérico solicitado. Isso pode ser observado na resposta apresentada por $\mathrm{A} 7$, no item $1 \mathrm{~B}$, quando representou $5 \mathrm{E}_{16}$ na base 8 e indicou como resposta $53_{8}$. Se o aluno lembrasse que o sistema octal possui metade de algarismos para representá-lo em relação ao 
sistema hexadecimal, ele perceberia que sua resposta estava incorreta, pois o resultado encontrado foi menor que o valor numérico na base 16 .

Determinados alunos não conseguiram identificar o algarismo $\mathrm{E}_{16}$ como um único dígito hexadecimal, cujo valor correspondente seria $14=1110_{2}$. Devido a isso, desmembraram esse dígito em dois. Alguns alunos, após realizarem esse desmembramento, atribuíram valores binários a cada algarismo, encontrando, de maneira equivocada, uma composição de 8 bits para um único algarismo hexadecimal, $\mathrm{E}_{16}=14=00010100_{2}$. Outros, ao desmembrarem esse dígito em dois, deduziram que encontraram com esse procedimento, o decimal correspondente ao número em questão.

Com relação à conversão do hexadecimal para BCD (item 1D), podemos considerar que os alunos não têm o conhecimento total do que seja a representação de um número no código BCD. Eles sabem que existem combinações proibidas representadas pelos seis últimos grupos a partir do grupo 1010, mas não conseguem perceber que, para realizar a representação de um número em $B C D$, esse número precisa, antes de tudo, estar representado em decimal. A representação de um número em $\mathrm{BCD}$ é a representação de cada algarismo decimal em binário.

Portanto, analisar avaliações ou qualquer outra produção escrita dos alunos é de grande importância, pois é uma forma do professor dialogar com as respostas apresentadas por eles. Assim, o professor é capaz de identificar o conhecimento que o aluno usou ao resolver a questão e se ele foi capaz de entender de forma correta o que foi solicitado. Procedendo dessa maneira, o erro passa ser visto pelo professor "como um elemento importante que dá pistas sobre os conhecimentos, práticas, processos, valores, presentes na relação pedagógica, quase sempre invisíveis." (BURIASCO, 2004, p. 250).

Após a análise realizada na avaliação, é importante, além de o professor retificar os erros com os alunos, procurar identificar em conjunto, as respostas que não foram possíveis de serem analisadas. Assim, o professor estará dando um tratamento didático ao erro, o que, segundo De La Torre (2007) e Ramos (2013), passa por três fases: localização, identificação e retificação.

\section{Referências}

BARDIN, L. Análise de conteúdo. Lisboa: Edições 70, 1977.

BURIASCO, R. L. C. de. Sobre avaliação em matemática: uma reflexão. Educação em Revista, Belo Horizonte, n. 36, p. 255-263, 2002.

BURIASCO, R. L. C. de. Análise da Produção Escrita: a busca do conhecimento escondido. In: XII ENDIPE - Encontro Nacional de Didática e Prática de Ensino, v.3, Curitiba. Anais... Curitiba:

Champagnat, p. 243-251, 2004. 
BURIASCO, R. L C. de; CYRINO, M. C. de C. T.; SOARES, M. T. C. Manual para correção das provas com questões abertas de matemática AVA - 2002. Curitiba: SEED/CAADI, 2003.

BURIASCO, R. L. C. de; FERREIRA, P. E. A.; CIANI, A. B. Avaliação como prática de investigação (alguns apontamentos). Bolema, Rio Claro, Ano 22, n. 33, p. 69-93, 2009.

CURY, H. N. Análise de erros: o que podemos aprender com as respostas dos alunos. Belo Horizonte: Autêntica, 2008.

CURY, H. N.; SILVA, P. N. Análise de erros em resolução de problemas: uma experiência de estágio em um curso de licenciatura em matemática. Revista Brasileira de Ensino de Ciência e Tecnologia, Curitiba, v. 1, n.1, p. 85-97, 2008.

DE LA TORRE, S. Aprender com os erros: o erro como estratégia de mudança. Porto Alegre: Artmed, 2007.

HOUAISS, A. Dicionário Houaiss da língua portuguesa. Rio de Janeiro: Objetiva, 2001.

IDOETA, I. V.; CAPUANO, F. G. Elementos de eletrônica digital. São Paulo: Érica, 1984.

LEIVAS, J. C. P.; CURY, H. N. Análise de erros em soluções de um problema de geometria: uma investigação com professores em formação continuada. In Revista Eletrônica em Educação Matemática, N.1, v.5, p. 71-83, 2010.

MIRANDA, W. S.; SILVA, F. H. S. A inter-relação entre avaliação, obstáculo e erro. In: Conferência Interamericana de Educación Matemática, 13, 2011, Recife. Anais... Recife: UFPE, p. 1-11, 2011.

RAMOS, M. L. P. D. Detecção, identificação e retificação: as três fases no tratamento e na correção dos erros. In: XI Encontro Nacional de Educação Matemática, 11., 2013, Curitiba. Anais... Curitiba: ENEM-PR, p. 1-14, 2013. 1 CD-ROM.

RAMOS, M. L. P. D.; CURI, E. Análise de erro em avaliação de sistemas digitais: uma questão com lógica AND e flip-flop. Revista Eletrônica em Educação Matemática, Florianópolis, v.8, n.1, p. 232247, 2013.

RICO, L.; LUPIÁÑEZ, J. L.; MARÍN, A.; GÓMEZ, P. Matemáticas Escolares y Análisis de Contenido con Profesores de Secundaria en Formación. Comunicación presentada en VIII Seminario de Investigación Pensamiento Numérico y Algebraico de la SEIEM. Aravaca, 2007, p. 1-19. Disponível em: <http://funes.uniandes.edu.co/466/1/RicoL07-2848.PDF>. Acesso em: 13 jul. 2013.

TAUB, H. Circuitos Digitais e Microprocessadores. São Paulo: McGraw-Hill, 1984.

TOCCI, R. J.; WIDMER, N. S; MOSS, G. L. Sistemas Digitais: princípios e aplicações. São Paulo: Pearson, 2011. 
MARIA LUISA PERDIGÃO DIZ RAMOS - Doutora em Ensino de Ciências e Matemática pela Universidade Cruzeiro do Sul (UNICSUL). Professora Titular da Coordenação de Área do Curso de Eletrotécnica do Centro Federal de Educação Tecnológica de Minas Gerais (CEFET-MG). E-mail: mlperdigao@yahoo.com.br

EDDA CURI - Doutora em Educação Matemática pela Universidade Católica de São Paulo (PUCSP). Professora Titular do Mestrado e Doutorado da Pós-Graduação da Universidade Cruzeiro do Sul (UNICSUL).E-mail: edda.curi@gmail.com 